\title{
AESTHETIC VISUAL ASPECTS IN DIGITAL PRESENTATION OF CULTURAL AND HISTORICAL HERITAGE
}

\author{
Dimitar Dobrevski
}

ddobrevski@gmail.com

\author{
National Art Academy, Sofia, Bulgaria
}

\begin{abstract}
All serious theoretical research in the field of communication shows that, under the influence of global processes of globalization, information is increasingly visualized and iconized. Young people communicate using the wide range of opportunities provided by digital technology and the Internet.

We spend a lot of our time in the virtual space. Everything seems fraudulently easy - everyone in minutes can upload information that is rapidly becoming available worldwide. Even small children handle as computer technicians. At the same time, the majority of participants in this communication have a substantial deficiency in visual literacy. Even specialists often ignore the language of forms, colors and compositional organization of space, which requires serious preparation, training and continuous specialization. Worldwide there are no good examples, but unfortunately they are not yet available to the cultural community in our country. The report raises a number of questions and issues for discussion and tries to draw attention to possible ways of solution.
\end{abstract}

Keywords: Visual Communication; lconography; Language of Colors and Forms

\section{ЕСТЕТИЧЕСКИ ВИЗУААНИ АСПЕКТИ ПРИ АИГИТААНОТО ПРЕЗЕНТИРАНЕ НА КУАТУРНО-ИСТОРИЧЕСКОТО НАСАЕАСТВО}

\author{
$\triangle$ имитьр Аобревски
}

Национа^на хуложествена акалемия, България

Резюме: Всички сериозни теоретични изслеАвания в областта на комуникацията показват, че поА въздействие на световните процеси на глобализация, инорормацията все повече се визуализира и иконизира. Млалите хора комуникират използвайки цялата широка палитра на възможности, които ни предоставя Аигиталната техника и интернет. Ние прекарваме голяма част от времето си във виртуалното пространство. Всичко изглежАа измамно Аесно - всеки за броени минути може $а$ качи инорормация, която става бързо Аостояние в целия свят. Аори малките Аеца боравят като експерти с компютьрната техника. В същото време болшинството участници в тази комуникация имат съществен Аефрицит по отношение визуалната грамотност. Аори 
специалистите често пренебрегват езика на фрорми, цветове и композиционна организация на пространството, който изисква сериозна подготовка, обучение и непрекъсната специализация. В световен мащаб не мипсват Аобри примери, но за съжаление те все още не са Аостояние на културната общественост у нас. АокАаАьт повАига реАица въпроси и проблеми за Аискусия и се опитва $А$ насочи вниманието към възможните пътища на решение.

КАючови Ауми: визуална комуникация, иконизация, език на цветове и орорми

Изходно понятие са обектите на културно - историческото наследство. Вероятно не е случаен фрактьт, че конореренцията се провежла във втората столица на България - Велико Търново. Тук пол краката ни са скрити векове от нашата история. Началото се крие в находки от края на VI хи^.пр.н.е., тракийското селище от XIII в.пр.н.е. на хъ^ма Царевец, ранновизантийската отбранителна система по Трапезица, Царевец и Момина крепост от IV-VII в., среАновековното славянобългарско селище $\Delta$ О IX-X в., укрепения Търновграл - столица на Втората българска Аьржава през XII-XIV в., разположен на Царевец, Трапезица, Момина крепост, Света гора и т.н. Богата на артедракти е и по-близката и поАалечна околност. Всъщност определено може да се твърди, че България се нарежла межлу водещите страни в Европа - най-богати на многовековно напластяване на култури, но за съжаление все още не може в пьлна степен $а$ а се възползва от това предимство. Нашите сьсеАи съумяват $\Delta а$ използват Аори и най-Аребни обекти по най-рационален начин И Аа извличат оринансова изгола от тяхното презентиране. В Списъка на световното културно и природно наслеАство на ЮНЕСКО АО АНеС са вкАючени общо 10 български обекта. От тях 7 са културни (Боянската църква, Мадарският конник, Ри^ски манастир, Казанльшката гробница, Старият Несебър, скалният манастир при с. Иваново, тракийската гробница при Свещари), 3 са приролни (парк Пирин, резерват Сребърна и вековните букови гори в Централен Балкан).

Към нематериалните обекти са включени Хорьт на бистришките баби, фестивальт Сурва в Перник, Нестинарството, мартеницата и фолк^орният оестивал в Копривщица. Вероятно Аоброто презентиране и подльржане на културни и исторически обекти изисква големи 
капиталов^ожения, свьрзани с консервация и реставрация, социализация и организация на експ^оатацията, и посещенията от туристи. Анес Аигиталните форми на презентация Аават нова палитра от възможности и в известна степен решение на ффинансовите проблеми. като език на общуване и форми - пряка косвена, спонтанна, неспонтанна, потьрсена, Всичко изглежАа измамно ^есно. Анес Аори неврьстните Аеца боравят уме^о с Аигитална техника. Всеки може Аа качи инорормация в Интернет и за броени минути тя $А$ стане Аостояние на цял свят. Българските инорорматици са волещи в Европа и Света. Комуникацията многократно се е улесни^а и ускори^а. Същевременно тя запазва основните си характеристики непотьрсена. Комуникацията е общуване, предаване на послание и влияния, съобщения. Комуникацията е езикова и кодова система - основа на живота и борбата срещу ентропията. Комуникацията е форма на обмяна на инорормация при всички живи организми и инорормационни системи. Тази глеАна точка ни препраща към еАна от относително малко познатите сорери на научното познание - семиотиката, като познание за знаци и символни системи, процеси, сигнали и техните биологични и социални функциИ.

Когато говорим за семиотика трябва да имаме предвил, че тя като форма на познание е с много слабо присьствие, дори в системата на висшето образование. Говорейки за семиотика ние най-често правим асоциация с романите на най-популярния семиотик в света - Умберто Еко. Какво е семиотиката е въпрос, който се залава най-често от самите семиотици и вероятната причина е, че в семиотиката все още има много полемични въпроси. Редица автори застьпват размични тези за предмета на Аисциплината, като започнем със структуралиста ФерАинанА $А$ ьо Сосюр - „Аингвистиката е знак и език на социалната фрункция и културата", прагматика Чар^з Пьрс - „осмисляне и интерпретиране на знаци с основни категории (икона, инАекс, символ)", писателя - меАиевист Умберто Еко - „прехоА межАу сигнаА и смисъА на културните френомени или културология прерастваща във всеобща наука на познанието", и завършим с мингвиста Томас Сибиък - „глобална концепция за възникването на живота като проявление на семиозис". Важното и неоспоримото е, че този акт като комуникация или съобщение има своите 
цели, алресант и алресат. Съществува палитра от добре изяснени и недотолкова Аобре средства, които са в любопитна връзка с целите. Аа планираме тяхното отношение изисква работа в Аве оглеАални посоки. Целта се деоринира в началото, но се случва в края.

Средствата могат да разширят или стеснят целта, еоректи на контраст межАу ново и познато, Аа определят реда на постьпване на инорормацията. Ролята на алресанта зависи от неговите експертни познания, а тази на алресата от интересите и общата му култура. Общият модел на общуване вк^ючва дефринирането на няко^ко пос^еАователни вьпроси:

- Кой предава съобщение? - алресант/комуникатор

- Какво се предава? - съобщение

- Kak се предава? - канал/медия

- На кого се предава? - рецепиент /алресат/аудитория

- Защо се прелава? - цел

Преминава през няколко етапа на общуване:

- Комуникативен

- Интерактивен

- Перцептивен

Съобщението е знак или набор от знаци, насочено Към еАин или няколко от сетивните органи на човека. Най-много внимание, макар недостатьчно, се обрьща на вербалното общуване, Аокато невербалните форми обичайно остават недооценени и дори пренебрегнати. Ние не знаем и не искаме да признаем езика на форммите, езика на цветовете, посланията на композиционното структуриране, както и езика на тялото. Това влиза в явно противоречие с редица съвременни тенденции, породени от глобалните процеси, които превръщат бързо света в еАно голямо „глобално село“. РеАица специалисти психолози твьрАят аргументирано, че общуването може $ы$ а се анализира като разпрелеление на 7\% словесно (вербално), 38\% вокално (интонационно) и 55\% несловесно (невербално) общуване. Тези факти Ао голяма степен са предопределени от специфриката на нашите възприятия. Човек е „зрящо“ и "САухтящо" Същество. Зрението е Аоминиращата сетивна модалност, чрез която нашият мозък получава $75 \%$ от постьпващата инорормация, 13\% 
заема слухьт, 6\% са тактилните усещания и за обонянието и вкуса остават по 3\%. Това нагленно се Аоказва и от съвременната статистика, която показва, че в съвременната комуникация образите се използват все почесто. За работата на сетивата водеща роля има мозъкът.

В същото време училището продьлжава да трупа усилено знания и умения главно по отношение на вербалното (речево общуване). Резултатьт е ясен - учениците и студентите излизат в следствие на тази образователна система неАостатьчно полготвени Аа ползват визуалната комуникация и вместо ограмотени, са по-скоро неграмотни и податливи на всякаква манипулация, а $ы$ не забравяме основните цели на всяко общуване (комуникиране) са именно манипулирането. Всичко всъщност е Аобре виАимо, но нещо ни пречи Аа го иАентиорицираме.

Вече е обичайно в еАин университет да се обучават еАновременно сложна амалгама от студенти (българи, турци, макеАонци, гьрци, а напоследьк Аори китайци). Кьм това може Аа прибавим и разноцветната палитра на студенти по програма Еразъм. Нарасналото Авижение на хора среща основно затруднение в езиковото вербално общуване. Това извежАа на преден план визуалните фрорми на комуникация, които макар разнообразни като контекст, остават разбираеми в еАна по-голяма степен, независимо от възрастта и етническите специфики.

Може Аа започнем с анализ на езика на форорите.

- Точките (анализирани не в своя математически смисъл), а като много малки обекти спират поглеАа.

- Аиниите изразяват Авижение, ориентирано вслеАствие въздействието на енна или повече сили.

- Фигурите и орормите изразяват в повечето култури Аоста по сложни понятия: крьгьт - небе, квадратьт - град/усвоена очовечена територия,

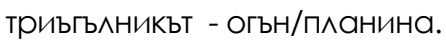

- Буквите от различните азбуки са произвонни от прости картинки/идеограми - напр. „А“" в своята пьрвична орорма изобразява глава на бик, завъртяна на $180^{\circ}$ се превръща в познатата буква.

Комуникацията се визуализира и иконизира. Това може $\Delta$ a ce забележи и по орормата на най-често използваните от миалите представители на обществото Аигитални варианти на комуникиране. 
Аостатьчно е $\Delta$ а поглеАнем цветните емотикони, като не може $А$ а отминем Аосалния френомен и на така наречената „шльокавица", с която м^алите СИ „чатят".

Всеки пише и е компетентен по всяка тема и „поства“ всичко. И това Всичко моментално се появява във виртуалното пространство, независимо, че може да бъде често фолшива новина. Анес в много комуникационни жанрове (компютьр, телевизия, видео, комикси и реклама) срелствата не само се визуализират, но започват все повече да ползват конкретни образи или $\Delta а$ се „иконизират“. Това е връщане всъщност Към еАна стара Аобре забравена пьрвична форма. Основна причина в края на XX век $\Delta$ а се развие толкова активно иконичната (визуална) инорормация са тенденциите все повече изкуства и медии Аа търсят еАин активен сИнтез на въздействие на повече знакови системи едновременно - думи, образи, музика, цветове. Така инорормацията се възприема по-бьрзо и с по-голямо удоволствие от всички. Тук определяща роля има компютьрната комуникация и наложилата се напослеАък форма на изкуствена Аействителност „виртуална реалност“. Това понятие обеАинява образите създалени или интерпретирани с помощта на компютьр. Те стават все по-ефективни и привлекателни порали големите възможности на тази техника.

Анес съвременните компютри могат Аа генерират с педантична акуратност Аесетки милиони цветови нюанси - много повече отколкото може $а$ в възриеме и най-тренираното човешко око. Целта е по-високо качество подобно на Ні-Fi аудио уредбите, които също генерират звуци Аалече извън Аиапазона на човешката сетивност. Особеното внимание към цветовете съвсем не е случайно. Цветовете от предимно естетическо среАство, ралващо с хармонията си човешките възприятия, Анес вече са се превърнали в знак символ и важен елемент от визуалния език. Основните функции, които те изпьлняват са : описателна, разделителна - обеАиняваща, структуриране на пространството, експресивна, изразяваща, символна, акцентираща, обобщаваща, хиперболизираща и пр. Трулно е всички изчерпателно Аа се опишат в рамките на този Аоклал. Най-устойчивите, най-конкретните и най-Аостьпните символи спореА специалистите са цветовете. Те 
притежават своя собствена изразителност и могат Аа влияят върху психиката. Всеки ги възприема инАивиАуаАно и учените използват нашите симпатии и антипатии към определени багри, за да Аиагностицират особености и заболявания на психиката.

Езикът на символите е своеобразно есперанто, разбираемо за народи, които пишат и говорят различно. Символите са пьрвият опит на човека да си обясни света и Аа го полреди. Те са посреАници межАу невиАимия и виАимия свят. Символизмыт е езикьт на митовете, на сънищата, на хералдиката, на пророците. Затова е Аобре да познаваме основните. Аори без да подозираме, те са навсякьле край нас и изпращат своите Сигнали АО съзнанието и поАсъзнанието ни.

Цветовете ни обединяват и разделят. Аетерминацията е насочена по полов, расов, културно - иАентичен (цивилизационен) и възрастов белег. Този феномен създава Аопьлнително затруднение при овлаляване на цветовия език. Понякога може $а$ а се Аостигне $А$ коренно противоположни асоциации, какъвто е случаят с белия и черния цвят в европейската и китайска символика. Цветовите предпочитания на жените ^есно могат $\Delta а$ се проследят по най-често използваните в рекламите, насочени към тях, цветови съчетания. С мъжете е многократно по-трудно, защото послеАните години от крайно консервативни, те постепенно започнаха $\Delta$ а стават все по-Аемократични в преАпочитанията си към цветовете и често това е трудно предвидимо. Аецата са още по-трудни за проследяване и изучаване. От м^аленческата възраст $А$ края на пубертета те успяват Аа преминат през няколко възрастови групи - всяка със специфоичните си цветови преАпочитания и възможности.

Но Аостатъчна ми е образователната подготовка по цветознание? Краткият отговор е НЕ! Някой може $\Delta а$ възрази, че

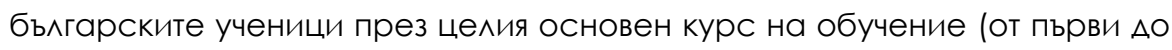
осми кАас) посещават часовете по изобразително изкуство и така получават стабилна подготовка и в областта на цветознанието. На пръв поглед това наистина е така. Аостатьчно е $а$ п погледнем само в програмата за преАучилищна и начална училищна подготовка и ще намерим редица амбициозни цели: развитие на сензомоторната, аналитико-познавателната и изобразително-творческата им Аейност", 
което в началното училище трябва $А$ прольлжи в "целенасочена и комплексна подготовка, свързана С възприемане, осъзнаване и пресъздаване на природната и социална действителност; $а$ а се осигурят възможности за по-нататьшно развитие на Аетето чрез усвояване на начални знания, умения и отношения, свързани с изобразителната Аейност, Аетско творчество и предпоставки за естетическа култура в началното училище.

По-нататьк в същия Аокумент намираме: Аецата изгражАат конкретни представи за материали, цветове, изразни средства и др. ...обобщени представи за сетивните свойства на основните изразни средства: пространство, композиция, форма и цвят. Основното пособие предназначено да подпомогне тази дейност представлява Авустранен ^аминиран Аист А4 С показани 6 цвята и няколко занимателни игри активизиращи наблюдателността и зрителната памет. Три от цветовете са основните (червено, жьлто и синьо), а останалите три са оранжево, зелено и розово? (По никакъв начин не е показана връзката межАу цветовете, а розовото всъщност е пурпур-виолет). Програмата на началните класове в училище е разпрелелена в слеАния поряАьк:

I к^ас - Хорариум часове: 2 часа сеАмично - 62 часа голишно

Начални знания за: реални и орантазни образи, фоорма, цвят, пространство, украса, ритъм, композиция, илюстрация. Цветове: жълт, червен, оранжев, син, зелен, светлозелен, виолетов, кафов, черен, бял. (прибавени са 3-4 цвята слеА полготвителната Аетска гралина, но изборьт пак е Ао голяма степен случаен).

II к^ас - Хорариум часове: 1.5 седмично - 48 часа годишно.

Импулсивно изразяване на общото впечатление и настроение чрез цветове, минии, щрихи и петна.

III к^ас - Хорариум часове: 2седмично - 64 часа голишно.

Начални знания за: цветове - топли, стулени.

IV к^ас - Хорариум часове: 1.5 часа сеАмично - 48 часа голишно.

Начални знания за: ^окални цветове.

V к^ас - Хорариум часове: 2 часа сеАмично - 68 часа гоАишно.

Сьдьржание и орорма : Тема, сюжет, мотив, цвят, миния, обем, орнамент. 
VI к^ас - Хорариум часове: 1.5 часа седмично - 51 часа годишно.

Композиция: Пространствено въздействие на цветовете - топли и стулени, въздушна перспектива, обемно изграждане на орормата с помощта на цветовете.

VII к^ас - Хорариум часове: 1.5 часа сеАмично - 51 часа гоАишно.

Хармония на цветовете - видове хармонии, гама, колорит.

VIII к^ас - Хорариум часове: 1.5 часа сеАмично - 51 часа годишно.

Цветовете като изразно средство - спектрални цветове, хроматични и ахроматични цветове.

IX-XII к^ас - В среАните училища, които не са насочени в областта на изобразителното изкуство, е вкАючен основно материал от история на ИЗКУството.

През целия периол учениците ползват по два учебника "Изобразително изкуство“, които са подготвени от конкуриращи се колективи. Най-често проблемът с цветовете заема 1-2 страници текст и илюстрации Ао 3-4. По- подробно е засегнато цветознанието в еАин от учебниците за пети клас, вероятно защото в колектива участва продр. Румен Райчев - Аьлгогодишен преподавател по цветознание в НХА. Предлага се и демонстрационно табло по цветознание, с автор М. Савчева, което в еАин вече по-систематизиран виА представя основни понятия на цветознанието. По всичко мичи, че съставителите на учебните планове са подходили непрофеесионално и Аори случайно, оставяйки за изобразителното изкуство повече или по-малко часове в зависимост от натовареността на програмата от Аругите „основни Аисциплини". Инициативата е оставена в ръцете на преподавателите, които се очаква $\Delta а$ имат нелоши продресионални познания по цветознание, защото в учебната програма на студентите по изобразителни изкуства с педагогически профои има Аисциплина "Живопис и цветознание". Аостатьчна ли е тази полготовка оставям Вие $а$ прецените. Само бих $А$ п пример с начина по който се изучава цветознание в Япония. Инорормация за това може $а$ а намерите в еАна от книгите на известния художник и педагог Борис Неменски: „изискването на японските предприемачи $а$ а се прави разлика межАу Ао 250 цвята при наемането на работници наложи изграждане на умения и предпоставка за качеството на продукцията. Ето 
защо, упражнения за различаване на цветовете са зальлжителен елемент от учебната програма в японските средни училища." (Nemensky, 2000: p. 65).

Може би японците са прави, и такова изтьнчено разграничение межАу цветове може Аа открие нови аспекти на нещата и света като цяло.

Опрелелено може да се желае полобна полготовка в средния образователен курс, както и в процеса на обучение на програмисти и инорорматици, защото в тяхната профресионална работа ще им се наложи да работят с цветове, форми и шриот.

\section{^итература / References}

Nemensky B. M. (2000). Knowledge of Art, Moscow: URAO, 2000 (In Russian) / [Неменский, Б.М . Познание искусством. - М.: Иза-во YPAO, 2000] 


\section{КУАТУРНО-ИСТОРИЧЕСКО НАСАЕАСТВО: \\ ОПАЗВАНЕ, ПРЕАСТАВЯНЕ, АИГИТААИЗАЦИЯ}

CULTURAL AND

HISTORICAL

HERITAGE

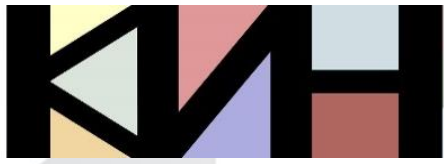

PRESERVATION PRESENTATION

DIGITIZATION
Материалите в сборника са обект на авторско право. Разрешава се безвъзмезАното ползване на техни електронни/ хартиени копия само за лична употреба или обучение, при пь^но цитиране на текущата страница и слеА писмена декларация от цитиращия за Аипса на търговски намерения. За копиране пол Аруга фрорма, препубликуване или публикуване на сървъри се изисква писмено разрешение и/или заплащане.

() Авторски колектив, 2019 Технически реАактори: Николай Ноев Калина Сотирова-Вълкова Ка^оян Николов

\section{Editors}

Galina Bogdanova Vanya Mateeva

This work is subject to copyright. Open and free of charge use of digital/hard copies of publications is granted only for personal or educational use, with full citation of the current page, and after written declaration of the quoting side for not-commercial Intention. For any other reproducing types, republishing, photocopying, recording, or any other storage retrieval system/ server written permission and/or fee is required.

(C) Authors` Group, 2019

Technical editors:

Nikolay Noev

Kalina Sotirova-Valkova

Kaloyan Nikolov

Научна поредица: том 5, брой 2 (7)/2019

Science series: vol. 5 , issue $2(7) / 2019$

www.math.bas.bg/vt/kin

ISSN: 2367-8038 